\title{
Origin of englacial stratigraphy at three deep ice core sites of the Greenland Ice Sheet by synthetic radar modelling
}

\section{Article \\ *Now at: Institute of Geography, University of Bremen, Bremen, Germany. \\ Cite this article: Mojtabavi S, Eisen O, Franke $S$, Jansen D, Steinhage D, Paden J Dahl-Jensen D, Weikusat I, Eichler J, Wilhelms $F$ (2022). Origin of englacial stratigraphy at three deep ice core sites of the Greenland Ice Sheet by synthetic radar modelling. Journal of Glaciology 68(270), 799-811. https://doi.org/ 10.1017/jog.2021.137}

Received: 3 March 2021

Revised: 13 December 2021

Accepted: 14 December 2021

First published online: 23 February 2022

\section{Keywords:}

Anisotropic ice; ice core; radio-echo sounding

\section{Author for correspondence:}

Seyedhamidreza Mojtabavi,

E-mail: mojtabavi@uni-bremen.de (c) The Author(s), 2022. Published by Cambridge University Press. This is an Open Access article, distributed under the terms of the Creative Commons Attribution licence (https://creativecommons.org/licenses/by/4.0/), which permits unrestricted re-use, distribution, and reproduction in any medium, provided the original work is properly cited.

\author{
Seyedhamidreza Mojtabavi ${ }^{1,2 *}$ (D), Olaf Eisen ${ }^{1,3}$ (D), Steven Franke ${ }^{1}$ (D), \\ Daniela Jansen ${ }^{1}$, Daniel Steinhage ${ }^{1}$ (ID) John Paden ${ }^{4}$ (ID, \\ Dorthe Dahl-Jensen ${ }^{5,6}$ (D), Ilka Weikusat ${ }^{1,7}$, Jan Eichler ${ }^{1}$ and Frank Wilhelms ${ }^{1,2}$ (D)
}

${ }^{1}$ Alfred-Wegener-Institut Helmholtz-Zentrum für Polar- und Meeresforschung, Bremerhaven, Germany; ${ }^{2}$ Department of Crystallography, Geoscience Centre, University of Göttingen, Göttingen, Germany; ${ }^{3}$ Department of Geosciences, University of Bremen, Bremen, Germany; ${ }^{4}$ Center for Remote Sensing of Ice Sheets (CReSIS), University of Kansas, Lawrence, KS, USA; ${ }^{5}$ Physics of Ice, Climate and Earth, Niels Bohr Institute, University of Copenhagen, Denmark; ${ }^{6}$ Center for Earth Observation Science, University of Manitoba, Winnipeg, Canada and ${ }^{7}$ Department of Geosciences, Eberhard Karls University of Tübingen, Tübingen, Germany

\section{Abstract}

During the past 20 years, multi-channel radar emerged as a key tool for deciphering an ice sheet's internal architecture. To assign ages to radar reflections and connect them over large areas in the ice sheet, the layer genesis has to be understood on a microphysical scale. Synthetic radar trace modelling based on the dielectric profile of ice cores allows for the assignation of observed physical properties' variations on the decimetre scale to radar reflectors extending from the coring site to a regional or even whole-ice-sheet scale. In this paper we rely on the available dielectric profiling data of the northern Greenland deep ice cores: NGRIP, NEEM and EGRIP. The three records are well suited for assigning an age model to the stratigraphic radar-mapped layers, and linking up the reflector properties to observations in the cores. Our modelling results show that the internal reflections are mainly due to conductivity changes. Furthermore, we deduce fabric characteristics at the EGRIP drill site from two-way-travel-time differences of along and across-flow polarized radarwave reflections of selected horizons (below $980 \mathrm{~m}$ ). These indicate in deeper parts of the ice column an across-flow concentrated $c$-axis fabric.

\section{Introduction}

The ice sheets are the biggest freshwater reservoirs of the earth system and thus are a significant factor for the future evolution of sea level (Stocker and others, 2013; Shepherd and others, 2019; Tapley and others, 2019; Edwards and others, 2021). Thus, understanding the behaviour of the ice sheets in response to changes in climate is essential for improving predictions for the future projections. Radio-echo sounding (RES) of ice and the mapping of internal reflections can provide valuable insights into the history of ice streams, accumulation patterns and the physical properties of internal layers in Greenland and Antarctica (e.g. Fujita and Mae, 1994; Fujita and others, 1999; Eisen and others, 2007; Urbini and others, 2008; Rodriguez-Morales and others, 2014; MacGregor and others, 2015; Cavitte and others, 2016, 2018; Winter and others, 2017; Kjær and others, 2018; Schroeder and others, 2019). Investigating physical properties of ice sheets and understanding complex ice flow behaviours (e.g. effects from anisotropy) can provide more insights to acquire missing process knowledge of ice stream dynamics in the ice sheet and glacier models. The speed of flow in the anisotropy of the ice is faster than isotropic ice, thus, anisotropic ice can enhance the speed of flow (Glen, 1958; Thorsteinsson and others, 1999). Most ice-sheet and glacier models assume the ice to be isotropic. Therefore, understanding ice flow behaviours can thus reduce model uncertainty and increase prediction accuracy for the future behaviour of sea level projections.

Together, the three locations comprise the three main dynamic flow regimes in northern Greenland: divide, flank and streaming flow. An overview of the Greenland ice core sites in relation to the dynamic setting of the Greenland Ice Sheet is shown in Figure 1. The drill site of the North Greenland Eemian (NEEM) core, which provided the oldest reconstructed record from folded layers in a core (Dahl-Jensen and others, 2013), is located on the north-eastern ice divide of Greenland. The North Greenland Ice Core Project (NGRIP) yielded an ice core with the oldest undisturbed record in Greenland back to $122 \mathrm{ka} \mathrm{b2k}$ (years before the year $2000 \mathrm{CE}$ ) (Wolff and others, 2010). It is located on the central divide, about $200 \mathrm{~km}$ west-southwest of the East Greenland deep Ice-core Project (EGRIP) drill site, where flow velocities are about $1.3 \mathrm{~m} \mathrm{a}^{-1}$. The drill site of the EGRIP is located in the region of the NEGIS, where the ice is currently moving at $\sim 55 \mathrm{~m} \mathrm{a}^{-1}$ to the north-northeast (NNE) (Hvidberg and others, 2020).

To understand the interplay between the catchment areas and their outflow, we need to study regions of increased ice flow velocities. The Northeast Greenland Ice Stream (NEGIS) is the largest ice stream in Greenland, draining about $12 \%$ of the Greenland Ice Sheet (Fahnestock and others, 1993, 2001; Vallelonga and others, 2014; MacGregor and others, 2015; Joughin and others, 2018; Larsen and others, 2018). The drill site of the EGRIP is located 


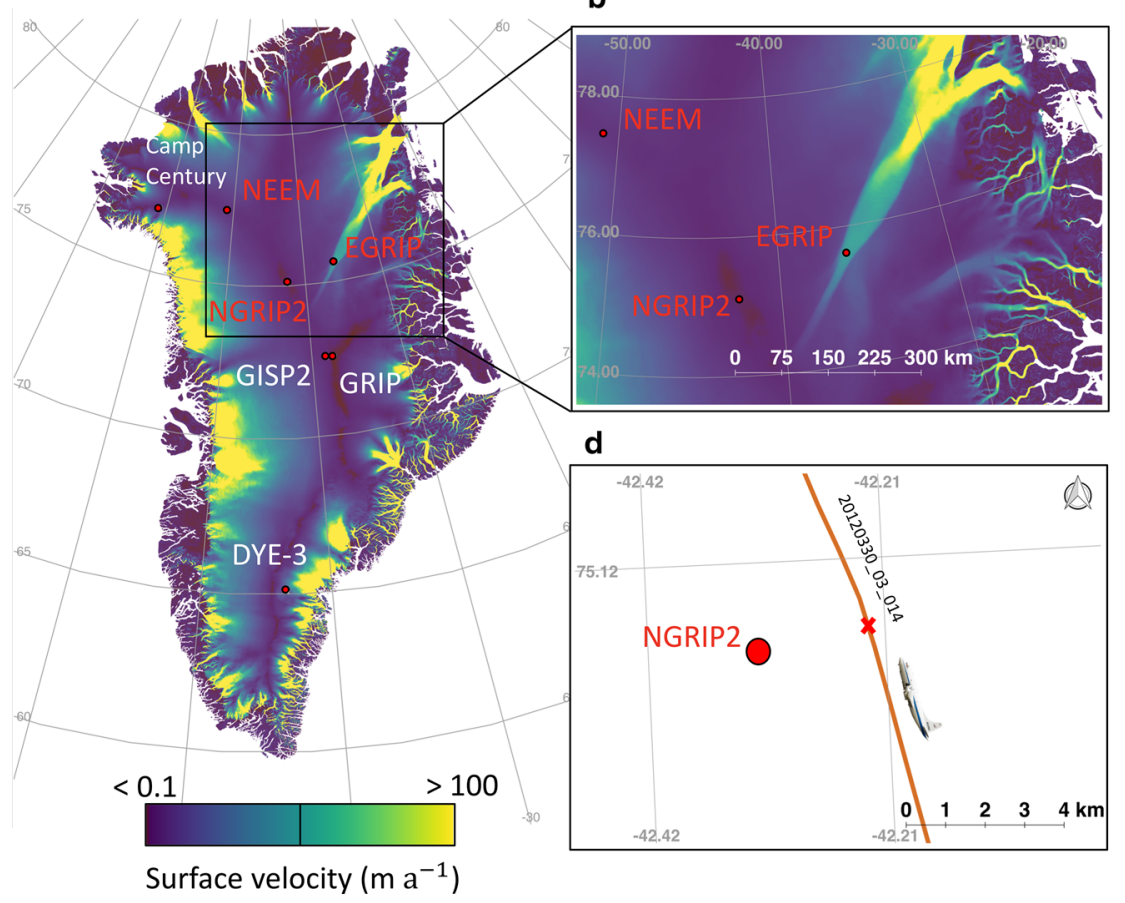

c

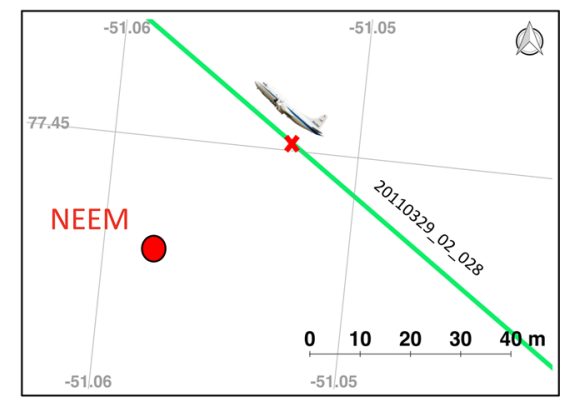

e

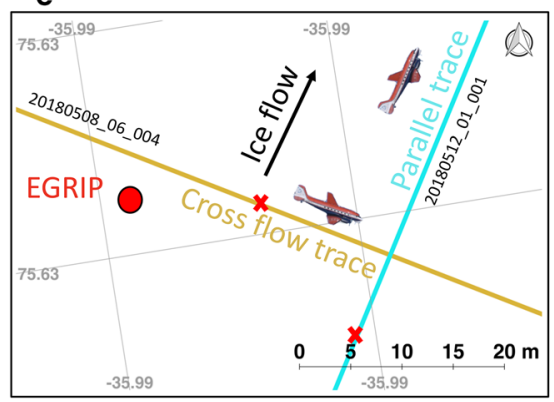

Fig. 1. (a) Locations of deep ice-core drill sites in Greenland Ice Sheet. (b) Focus on ice core locations in the vicinity of NEGIS and northern Greenland used in this study. (c) NEEM drill site with the RES profile line from CReSIS flight 20110329_02_028. (d) NGRIP drill site with the RES profile line of CReSIS flight 20120330_03_014. (e) EGRIP drill site with the RES profile line of AWI flights 20180508_06_004 and 20180512_01_001. The red crosses mark the traces closest to each drill site which we use in our analysis (single traces in Fig. 2). The red cross on the cross-flow line at EGRIP in panel (e) is the closest point to the drill site based on the space between each trace that is $15 \mathrm{~m}$ for the AWI radar measurement. The panels (c) and (e) are strongly zoomed in (scale bar in meters), compared to panel (d) with the scale bar covering a few $\mathrm{km}$. Colours show surface flow velocities from satellite data (Joughin and others, 2018). Projection: WGS 84/NSIDC Sea Ice Polar Stereographic North (EPSG:3413).

in the region of the NEGIS, where the ice is currently moving at $\sim 55 \mathrm{~m} \mathrm{a}^{-1}$ to the NNE (Hvidberg and others, 2020). The icedynamic regime of the NEGIS is complex and, interpolating the surface velocity into depth, all ice entering the ice stream seems passing through its well developed shear margins (Christianson and others, 2014; Franke and others, 2020a).

Over the past 20 years, multi-channel ultra-wide band (UWB) radar systems (MacGregor and others, 2015; Hale and others, 2016; Franke and others, 2020b) have provided high-resolution data sets, and offered opportunities to understand the physics of internal stratigraphy from the local scale to large areas of the ice sheet. Synthetic modelling of RES data has previously been applied to the Greenland and Antarctic records from the GRIP ice core, EPICA Dome C (EDC) and the EPICA Dronning Maud Land (EDML) ice cores (Hempel and others, 2000; Eisen and others, 2004, 2006; Winter and others, 2017). Winter and others (2017) used this technique to compare data in the vicinity of EDC, where they investigated how different radar systems image changes from physical properties in internal reflection horizons (IRHs) and the differences of the radar systems in bed topography, penetration depth and capacity of imaging the basal layer. Applying a comparable approach to Greenland radar records will help to understand the physical properties and thus inform ice flow models as well as contribute to process understanding of ice dynamics. Combining the local results from modelled radargrams, on the basis of ice core data from different regimes, with the IRHs in regionally distributed profiles of airborne RES provide the opportunity to upscale local measurements of physical properties. Most IRHs in the ice sheet can be considered isochrones (Siegert and others, 1998; Fujita and others, 1999; Eisen and others, 2003; Cavitte and others, 2016). Therefore, combining the synthetic radar modelling with a depth-age relationship form the northern Greenland ice cores (Rasmussen and others, 2013; Mojtabavi and others, 2020) can allow the dating of the IRHs in northern Greenland.

Regarding the physical origin of IRHs, conductivity can explain the majority of the radar returns in ice sheet (Fujita and others, 1999; Hempel and others, 2000; Miners and others, 2002; Eisen and others, 2006). In general, it can be stated that for the upper $\sim 100$ m of ice sheet, the reflections are mostly based on permittivity and density contrasts (Paren and Robin, 1975; Arcone and others, 2004; Eisen and others, 2004). Below $100 \mathrm{~m}$ depth, the variability of the density-based permittivity decreases and reflections dominated by permittivity contrasts which are in few cases related to changes in crystal orientation fabric (COF), which affects the real part of permittivity (Eisen and others, 2007). The deformation of an ice crystal depends on the direction and magnitude of stress and strain in the ice sheet (Gusmeroli and others, 2012; Faria and others, 2014; Llorens and others, 2016; Qi and others, 2019). Random orientation of all ice crystals indicates the COF is isotropic. If a large number of $c$-axes align (e.g. parallel), it results in an anisotropic COF (Gusmeroli and others, 2012). In some cases, IRHs can be caused by sudden changes in COF. Anisotropy-derived IRHs will be characterized either by polarization-dependent variations in the wave propagation speed or by anisotropic backscatter. The anisotropy in terms of permittivity of a monocrystal of ice has been determined as $\Delta \varepsilon^{\prime}=0.34$ (Matsuoka and others, 1997). For an anisotropic fabric, the size of fabric eigenvalues and orientation of eigenvectors determine the effective permittivity and thus wave speed in a particular polarization plane.

As the first step, we apply a numerical model for electromagnetic wave propagation (Eisen and others, 2004) to records of dielectric properties to calculate synthetic radargrams. Dielectric observations are taken from the three northern Greenland deep ice cores: EGRIP, NEEM and NGRIP. We compare the synthetic radargrams and the multi-channel UWB radar data in order to match common IRHs 


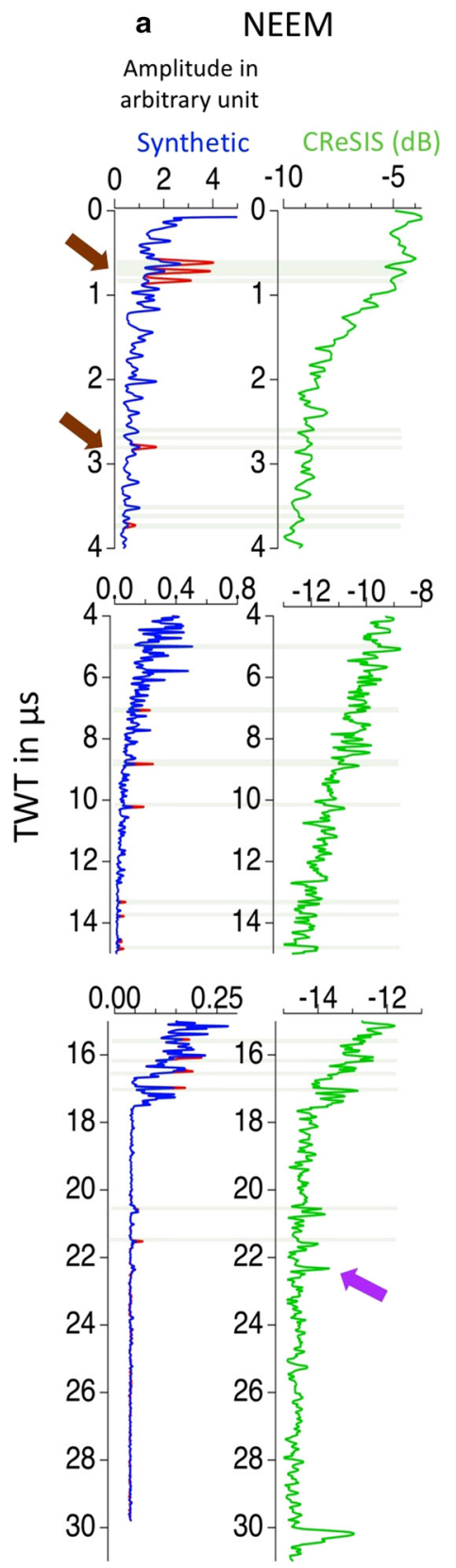

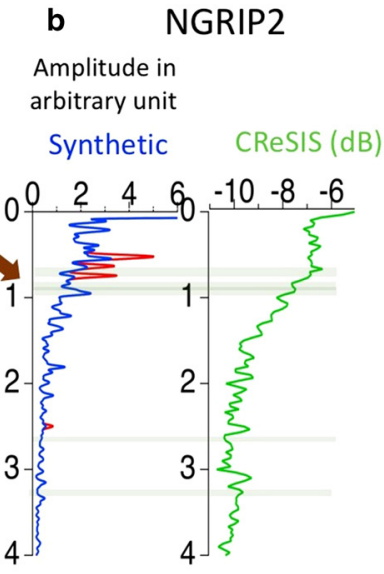

c EGRIP

Amplitude in

arbitrary unit $\quad \mathrm{AWI}(\mathrm{dB})$

Synthetic along/cross flow

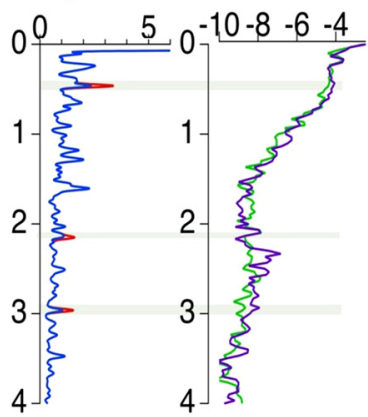

$0,0,0,2,0,4,-12,-10,-8$

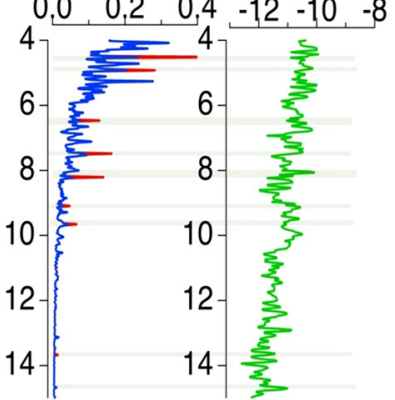

$0,0,1,0,2,0,-12,-10,-8$
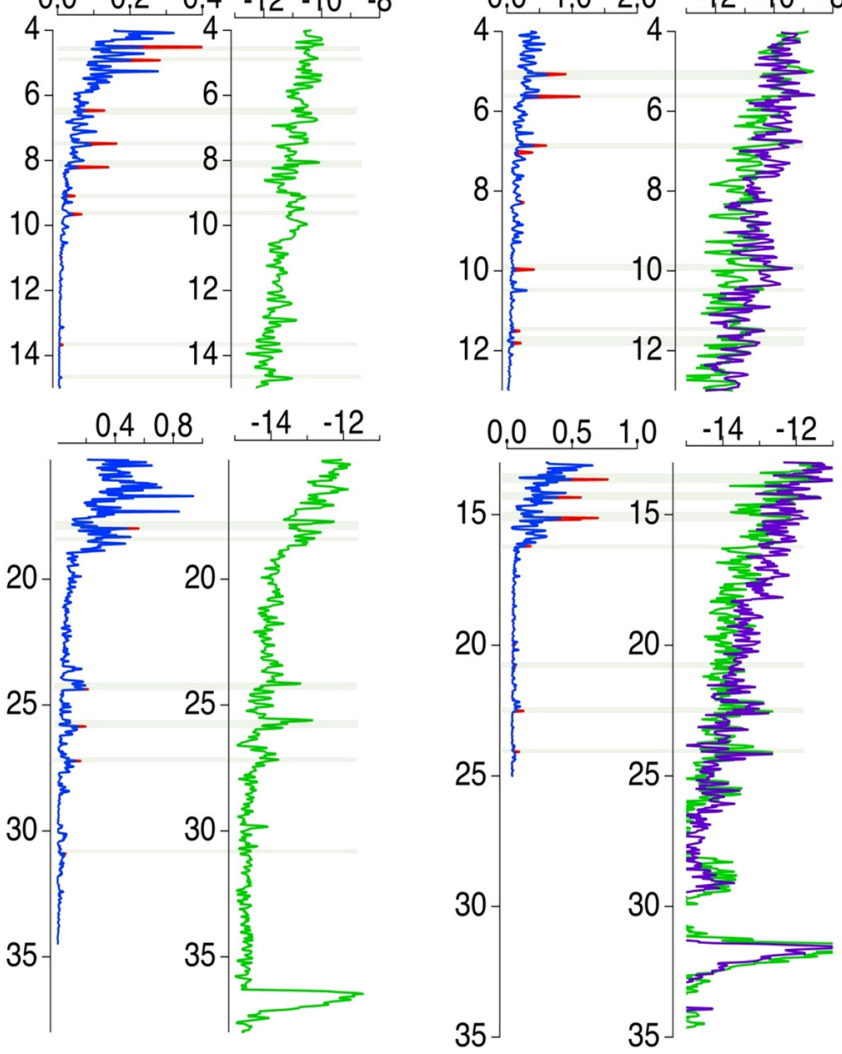

Fig. 2. A-scopes for traces of the radar systems (green) at (a) NEEM, (b) NGRIP2 and (c) EGRIP (along-flow in green and cross-flow in purple (positions indicated by red crosses in Fig. 1)) and the synthetic traces (blue). The surface reflection of each trace is shifted to time zero. The reflections used for synchronization are marked by grey bands. The synthetic peaks highlighted in red cause the identified dated reflections (Table 3) which are observed both in the synthetic and RES traces. The coloured arrows highlight IRHs that are described in detail in the Results section. For better graphical representation, we split each trace into three TWT intervals, as the amplitude decays with depth.

between airborne RES data and synthetic radargrams and identify the physical processes that cause the reflections (i.e. the physical properties of a certain IRH). As a second step, we determine ages for the reflectors that can be considered as isochrones. The IRHs are assigned ages from the depth-age relationship (Rasmussen and others, 2013; Mojtabavi and others, 2020) of the northern Greenland ice cores. Finally, for the EGRIP drill site, we also investigate polarization-dependent traveltime differences in the ice stream to infer the potential distribution of the anisotropic fabric.

\section{Method}

\section{Airborne radar data}

In May 2018, the Alfred Wegener Institute (AWI) collected the extensive airborne radar survey EGRIP-NOR-2018 on the
NEGIS in the vicinity of the EGRIP drill site with an eight-channel radar system (MCoRDS5) mounted on AWI's Polar6 aircraft (Franke and others, 2021). The EGRIP drill site $\left(75.38^{\circ} \mathrm{N}, 35.60^{\circ} \mathrm{W}\right)$ and the location of selected RES profiles that are located along the upstream part of the NEGIS are shown in Figure 1e. The radar sounder was developed at the Centre for Remote Sensing of Ice Sheets (CReSIS) at the University of Kansas and was designed for sounding ice thickness, internal layering and the basal unit of ice sheets. A detailed description of the radar system is given by Hale and others (2016) and Franke and others (2020b). The radar system uses different transmit pulse durations as well as different receiver gains for different parts of the ice column to increase the dynamic range of the system. The recording parameters for the survey are shown in Table 1. For the comparison with the synthetic 
Table 1. Summary of the RES systems and modelled data.

\begin{tabular}{|c|c|c|c|c|c|c|}
\hline Dataset & $\begin{array}{l}\text { Numerical } \\
\text { model/radar system }\end{array}$ & Waveform-signal & $\begin{array}{l}\text { Pulse-repetition- } \\
\text { frequency }\end{array}$ & Sampling-frequency/time & $\begin{array}{l}\text { Sampling- } \\
\text { resolution }\end{array}$ & Frequency-range \\
\hline AWI (Polar6 aircraft) & MCoRDS5 & $1 \mu \mathrm{s}-3 \mu \mathrm{s}-10 \mu \mathrm{s}-$-Chirp & $10 \mathrm{kHz}$ & $1600 \mathrm{MHz}$ & $0.45 \mathrm{~m}$ & $180-210 \mathrm{MHz}$ \\
\hline CReSIS (NASA's P-3 aircraft) & MCoRDS2 & $1 \mu \mathrm{s}-3 \mu \mathrm{s}-10 \mu \mathrm{s}-$ Chirp & $10 \mathrm{kHz}$ & $111 \mathrm{MHz}$ & $0.45 \mathrm{~m}$ & $180-210 \mathrm{MHz}$ \\
\hline Modelled & emice & Ricker & & $0.02 \mathrm{~ns}$ & $0.02 \mathrm{~m}$ & $100-150 \mathrm{MHz}$ \\
\hline
\end{tabular}

radargrams we use a single trace from the SAR processed data product of the EGRIP-NOR-2018 campaign (for details of the survey see Franke and others, 2020b, 2021). The main processing steps of the UWB radar data include presumming (incoherent averaging) during RES data acquisition, pulse compression, $f-k$ migration-based SAR processing as well as channel and waveform combination during the processing (for more details see Franke and others, 2020b). The diameter of the Fresnel zone is $\sim 60 \mathrm{~m}$ based on the bandwidth of $180-210 \mathrm{MHz}$ and the ice thickness range of $2-3 \mathrm{~km}$ (Franke and others, 2020a). The SAR processing algorithms compute a one-dimensional layered dielectric model, based on the location of the ice surface, with a dielectric constant of 3.15 for ice (Rodriguez-Morales and others, 2014). For details of the radar processing see Rodriguez-Morales and others (2014) and Franke and others $(2020 \mathrm{~b})$. We selected the traces closest to the EGRIP drill site from one profile oriented along ice-flow direction (profile 20180512_01_001) and a second profile oriented across ice-flow direction (profile 20180508_06_004) (Fig. 1). The distance of the traces oriented along and across ice flow to the EGRIP drill site is $\sim 30$ and $\sim 12 \mathrm{~m}$ respectively.

The NEEM and NGRIP drill sites are shown in Figure 1, panels $\mathrm{c}$ and $\mathrm{d}$. For comparison of the synthetic radargrams at the location of the two ice cores, we used two radar profiles (profile 20110329_02_028 for NEEM and profile 20120330_03_014 for NGRIP) from the operation ice bridge (CReSIS, 2016). We used the 'csarp_standard' data product, which represents SAR processed radar data downloaded from the CReSIS website (www.cresis.ku.edu). The recording parameters for the survey around the NEEM and NGRIP with the Multi-Channel Coherent Radar Depth Sounder (MCoRDS2) mounted on NASA's P-3 aircraft are shown in Table 1. A detailed description of the CReSIS data product and processing parameters is available on the CReSIS website. The closest trace's distance to the NEEM drill sites is $\sim 34 \mathrm{~m}$, while the closest trace distance to the drill site of the NGRIP core is $\sim 2.75 \mathrm{~km}$ (Fig. 1). To compare the measured airborne RES data with the modelled synthetic data, we shifted the zero time of the airborne RES data to the surface reflection (air-ice interface). In this way, the RES data and synthetic trace surfaces are aligned.

\section{Dielectric profiling (DEP) and ice core data}

The dielectric properties (Moore and Paren, 1987) of the EGRIP, NEEM and NGRIP ice cores were obtained with a DEP (dielectrical profiling) bench at a frequency of $250 \mathrm{kHz}$ and a vertical resolution of $5 \mathrm{~mm}$ as described by Wilhelms and others (1998), Wilhelms (1996, 2005), Mojtabavi and others (2020). To yield the best possible interpretation of the DEP data, ice core breaks, missing pieces and differing overall quality of the ice core sections were logged during the processing. Slight capacitance/conductance variations due to deformation of the cables of the DEP device were corrected by the use of calibration data. A detailed description of DEP data processing of the EGRIP, NEEM and NGRIP ice cores is given by Mojtabavi and others (2020). At the time of this study, the EGRIP drilling campaign has not yet reached bedrock, therefore we present and analyse only the available DEP data, which correspond to the upper $\sim 2122 \mathrm{~m}$ of the ice column that were profiled during the 2017-19 field seasons. For the NEEM core, we supplemented the topmost $100 \mathrm{~m}$ of the main core record with the NEEM-2008-S1 firn core record (Karlsson and others, 2016) which originates from the NEEM access hole. The DEP data of the main NEEM ice core reach down to a depth of $\sim 2537 \mathrm{~m}$, which is about $20 \mathrm{~m}$ above the bedrock, and were recorded over several field seasons between 2008 and 2012. As the first NGRIP coring (here referred to as 'NGRIP1') terminated at $\sim 1372 \mathrm{~m}$ depth due to a jammed drill, a second hole was restarted a few metres away, here referred to as 'NGRIP2'. The DEP data from the NGRIP2 ice core reach down to $2930 \mathrm{~m}$ and were measured during the 1998-2004 field seasons. The data from the upper part of NGRIP2 down to $1298.705 \mathrm{~m}$ are published in this study for the first time, while data from the deeper part were presented by Rasmussen and others (2013). Table 2 summarizes the unpublished and published DEP data sources used in this study.

It should be noted that all DEP data are not corrected for the temperature difference between the deep ice in-situ and during the measurements in the field. However, according to Winter and others (2017), temperature should not alter the signature of conductivity and permittivity reflection patterns, as temperature affects the amplitude of the reflections which has no incidence on the depth of IRHs which is the main parameter of our comparison. The ice cores are drilled in a trench, which implies that the DEP records start at a depth of 13.77, 6.55 and $11.02 \mathrm{~m}$ for the EGRIP, NEEM and NGRIP2 ice cores, respectively. To compare modelled and observed results, we extrapolate the DEP data up to the surface, using a relative permittivity of 1.55 and an electric conductivity of $4 \mu \mathrm{S} \mathrm{m}^{-1}$ as surface values (Winter and others, 2017). The values are the density and conductivity mixed permittivity (DECOMP) (Wilhelms, 2005) of the measured pure ice conductivity $\left(20 \mu \mathrm{S} \mathrm{m}^{-1}\right)$, the assumed surface firn density $\left(300 \mathrm{~kg} \mathrm{~m}^{-3}\right)$ and the ordinary relative pure ice permittivity (3.15), as determined below.

\section{Modelling of synthetic radar traces and the depth of IRHs}

Following the approach in Winter and others (2017), we used the conductivity and permittivity records, measured through DEP as described above as input for the 1D-FDTD numerical model (One-Dimensional Finite Difference Time Domain) 'emice' (Eisen and others, 2004) to calculate synthetic radar traces. A detailed description of the calculation and calibration to the DEP data is given by Mojtabavi and others (2020). Following Eisen and others (2006), we tested different wavelets and chose a Ricker wavelet for this study, which is short and thus favourable to determine the depth of the reflectors' origin at high resolution. The envelope of the synthetic traces, which is related to the reflected energy, is obtained by applying a Hilbert magnitude transformation (e.g. mimic rectification) (Eisen and others, 2006). Finally, the model outputs are smoothed with a Gaussian running mean of $100 \mathrm{~ns}$ (Winter and others, 2017). That way the resolution of the filtered model output is in the range of the observed data, and the response to certain reflectors can be compared to events recorded in the measurements. 
Table 2. Summary of the DEP data sets.

\begin{tabular}{llllll}
\hline Dataset & Sampling resolution & Frequency & Drill depth & New data in this study & Published data \\
\hline EGRIP & $5 \mathrm{~mm}$ & $250 \mathrm{kHz}$ & $2122.445 \mathrm{~m}$ & $1383.840-2122.445 \mathrm{~m}$ & Mojtabavi and others (2020) \\
NEEM & $5 \mathrm{~mm}$ & $250 \mathrm{kHz}$ & $2537.065 \mathrm{~m}$ & $1493.297-1757.310 \mathrm{~m}$ & $\begin{array}{l}\text { Mojtabavi and others (2020), Rasmussen and others (2013) } \\
\text { NEEM-2011-S1 }\end{array}$ \\
NGRIP2 & $5 \mathrm{~mm}$ & $250 \mathrm{kHz}$ & $100 \mathrm{~m}$ & & Mojtabavi and others (2020), Karlsson and others (2016) \\
\hline
\end{tabular}

Table 3. The matched layers of synthetic and real radargrams with TWTs at the ice core sites, depth ranges of their reflecting conductivity/permittivity sections of DEP and corresponding ages from the GICC05 (depth, age) timescale taken from Mojtabavi and others (2020) and Rasmussen and others (2013).

\begin{tabular}{|c|c|c|c|c|c|c|c|c|c|}
\hline \multicolumn{3}{|l|}{ NEEM } & \multicolumn{3}{|c|}{ NGRIP2 } & \multicolumn{3}{|c|}{ EGRIP } & \multirow[b]{2}{*}{$\begin{array}{l}\text { Age } \\
\text { (a) }\end{array}$} \\
\hline$t / \mu \mathrm{s}$ & $s / m$ & $\begin{array}{l}\text { Age } \\
\text { (a) }\end{array}$ & $t / \mu \mathrm{s}$ & $s / m$ & $\begin{array}{c}\text { Age } \\
\text { (a) }\end{array}$ & $t_{\|} / \mu \mathrm{s}$ & $t_{\perp} / \mu \mathrm{s}$ & $s / m$ & \\
\hline 0.71 & 70.34 & 220 & 0.63 & 60.40 & 220 & 0.40 & 0.40 & 45.45 & 216 \\
\hline 2.71 & 247.97 & 1062 & 2.50 & 220.00 & 1060 & 2.10 & 2.10 & 190.41 & 1470 \\
\hline 3.60 & 326.67 & 1470 & 4.49 & 390.00 & 2060 & 2.93 & 2.93 & 258.55 & 2050 \\
\hline 6.78 & 608.84 & 3076 & 4.90 & 424.00 & 2260 & 5.00 & 5.00 & 436.37 & 3639 \\
\hline 9.78 & 756.00 & 4045 & 6.44 & 554.00 & 3060 & 5.60 & 5.60 & 484.10 & 4048 \\
\hline 11.22 & 874.00 & 4931 & 7.45 & 640.00 & 3640 & 6.80 & 6.80 & 587.39 & 4931 \\
\hline 12.75 & 1001.80 & 5984 & 8.17 & 701.00 & 4040 & 8.23 & 8.23 & 708.21 & 5991 \\
\hline 13.18 & 1136.90 & 7247 & 9.06 & 777.00 & 4580 & 9.93 & 9.93 & 849.98 & 7245 \\
\hline 13.97 & 1175.93 & 7637 & 9.61 & 823.90 & 4920 & 11.46 & 11.50 & 980.17 & 8440 \\
\hline 14.19 & 1239.50 & 8359 & 11.26 & 941.00 & 5800 & 11.80 & 11.83 & 1005.70 & 8697 \\
\hline 15.38 & 1246.00 & 8443 & 13.07 & 1117.50 & 7240 & 13.65 & 13.68 & 1161.80 & 10483 \\
\hline 15.50 & 1265.50 & 8700 & 13.61 & 1163.50 & 7639 & 14.33 & 14.36 & 1219.40 & 11305 \\
\hline 15.78 & 1325.11 & 9630 & 14.63 & 1248.50 & 8440 & 22.53 & 22.60 & 1910.15 & \\
\hline 16.12 & 1370.14 & 10496 & 14.92 & 1272.50 & 8680 & 23.90 & 23.96 & 2027.26 & \\
\hline 19.67 & 1749.00 & 37696 & 16.64 & 1419.00 & 10484 & 24.08 & 24.15 & 2041.89 & \\
\hline \multirow[t]{6}{*}{20.57} & 1830.00 & 45622 & 17.13 & 1470.50 & 11305 & & & & \\
\hline & & & 18.00 & 1527.00 & 12918 & & & & \\
\hline & & & 24.40 & 2067.30 & 38140 & & & & \\
\hline & & & 25.90 & 2192.20 & 45580 & & & & \\
\hline & & & 27.20 & 2308.50 & 52301 & & & & \\
\hline & & & 30.90 & 2619.30 & 80077 & & & & \\
\hline
\end{tabular}

To assign conductivity variations in the DEP record to the IRHs, we mute selected conductivity peaks (Eisen and others, 2006; Winter and others, 2017) in our DEP data (red peaks highlighted by grey bands in Fig. 2). By comparison of the recorded radar trace with the synthetic trace, we can attribute the origin of a certain IRH if it changes in the synthetic trace, when being muted in the DEP record. Ultimately, the established dating for the DEP records (Mojtabavi and others, 2020) is transferred to the identified IRHs. Therefore, we are generating two main outcomes: we identify the physical origin for the radar reflection and provide a revised age for the IRHs. Details on the modelling of synthetic radar traces and the depth of IRHs are laid out in Appendix A ('Details on the modelling of synthetic radar traces').

\section{Anisotropy analysis at EGRIP}

Two radar profiles, one along flow $(\|)$ and another one cross-flow $(\perp)$, cross the vicinity of the EGRIP drill site within few tens of metres from the borehole. These provide us with the opportunity to investigate bulk anisotropy by comparing the TWT of reflections originating from the same reflector at depth. A similar approach was performed by Dall (2010) for the Greenland Ice Sheet. For EGRIP we record the depth $s$ of certain peaks, which can be verified by the above described muting approach, in the DEP record, and the measured TWT $t$ of the corresponding IRH in the along-flow and cross-flow direction in Table 4 in Appendix B ('Anisotropy'). We compare the traces in the immediate vicinity of the intersection point to investigate the impact of inclined internal layers, and access how a possible slope can effect the estimated permittivity $(\varepsilon)$ and anisotropy analysis. We specifically looked out for time shifts of the used wiggles, which would indicate the influence of a sloped reflection horizon. As the diameter of the Fresnel zone is $\sim 60 \mathrm{~m}$ (Franke and others, 2020a), we have extracted respectively two neighbouring traces $\pm 30 \mathrm{~m}$ from before and after the main trace (along/cross-flow traces in Fig. 2 closest to the EGRIP drill site) which we used for the anisotropy analysis. It should be noted that the trace spacing is $15 \mathrm{~m}$. We investigated the potential effect of non-negligible slopes of the internal layers. The neighbouring traces within the diameter of one Fresnel zone exhibit a very consistent depth response of the IRH signatures. We did not find any significant shift of the neighbouring traces and therefore, exclude inclined layers as the reason for our observed time shifts between the two polarization directions. Solving Maxwell's relation (refer to Eqn (A.1) in Appendix A) for the permittivity along/cross-flow and computing the propagation speed in the ice from the TWT and the reflector distance in the core:

$$
\varepsilon_{\mathrm{d}}^{\prime}=c_{0}^{2} / 4\left(t_{\mathrm{d}}-t_{0}\right)^{2} /\left(s-s_{0}\right)^{2}
$$

where $d \in \|, \perp$, yields a direct way to compute the permittivity in the polarization directions along the flight lines (along/crossflow). The standard error is then calculated following:

$$
\sigma\left(\varepsilon_{\mathrm{d}}^{\prime}\right)=\frac{c_{0}^{2} \Delta t}{\sqrt{2}} \frac{\left|t_{\mathrm{d}}-t_{0}\right|}{\left(s-s_{0}\right)^{2}}
$$

where the depth error is very small compared to the time error as the DEP record is resolved in $5 \mathrm{~mm}$ increments, while the radar trace is only sampled in $0.033 \mu$ s intervals. The uncertainty for the definition of a reflector we therefore estimate to be $\Delta t=$ $0.01665 \mu$ s for the error calculation. For the permittivity analysis we choose a clearly identifiable reflector for both polarization directions, which is recorded at a depth $s_{0}=190.415 \mathrm{~m}$ in the DEP profile (the maximum amplitude in the DEP signal) and corresponds to synchronous IRH at the TWT $t_{0}=2.1 \mu \mathrm{s}$. From a certain depth the IRHs of both polarization shift apart in TWT, indicating bulk anisotropy. The upper part of Table 4 (Appendix B 'Anisotropy') compiles the observations for the along and cross profiles of EGRIP, compared to the DEP record. The permittivity difference between the two polarization directions (Eqn (3)) follows immediately, while treating the shared common - error of the synchronous reference horizon in an analysis of systematic errors yields the error of the permittivity difference along and cross-flow (Eqn (4)). The permittivity difference between along and cross-flow directions only sets on at $849.98 \mathrm{~m}$ resp. $9.9500 \mu \mathrm{s}$.

$$
\varepsilon_{\perp}^{\prime}-\varepsilon_{\|}^{\prime}=\frac{c_{0}^{2}}{4} \frac{\left(t_{\perp}-t_{0}\right)^{2}-\left(t_{\|}-t_{0}\right)^{2}}{\left(s-s_{0}\right)^{2}},
$$




$$
\sigma\left(\varepsilon_{\perp}^{\prime}-\varepsilon_{\|}^{\prime}\right)=\frac{c_{0}^{2} \Delta t}{\sqrt{2}\left(s-s_{0}\right)^{2}} \sqrt{t_{0}^{2}+t_{\|}^{2}-t_{\|} t_{\perp}+t_{\perp}^{2}-t_{0}\left(t_{\|}+t_{\perp}\right)},
$$

This means the calculated difference over the interval from the shallow layer is smaller than in reality. Therefore, we calculate the permittivity difference from intervals in between the just mentioned deeper IRH at $849.98 \mathrm{~m}$ and the IRH below. For short intervals the error is bigger than the signal, but the deeper layers suggest a difference $\varepsilon_{\perp}^{\prime}-\varepsilon_{\|}^{\prime} \approx 0.03$ in the interval $850-2000 \mathrm{~m}$.

\section{Results}

To accomplish our goal to identify the physical origin of a certain IRH, and determine ages for those reflections which can be identified as IRHs, we used single-trace 'A-scopes' (e.g. Figs 2, 5) and radargrams (or ' $Z$-scopes', e.g. Figs 3,4 ) for the comparison between synthetic radar and airborne RES data over larger regions.

Figures 2 and 3 accentuate the excellent agreement between the synthetic radargrams (SYN) and the identified in the radargrams IRHs. Even when correcting for the temperature effect in the DEP data, it is not to be expected that the forward modelling could exactly reproduce the observed amplitudes. Figure 2 presents the peaks (grey bands) of IRHs as observed in A-scope representation we use for synchronization between radar measurements and synthetic traces, which are computed based on the DEP record of the ice core and the short Ricker wavelet as source signal. As discussed in more details in the Method section, the synthetic traces have a higher temporal (vertical) resolution compared to the radar measurements. For better graphical representation we therefore split each trace into three travel time (depth) segments (synthetic in blue and RES in green), to adjust the dynamic range of the reflections, as the RES amplitude is decaying over travel time. Figure 3 compares the measured radargrams close to the drill sites and synthetic radargrams (z-scope) from modelled traces (Fig. 2$)$, which are derived by plotting the synthetic trace 200 times with amplitudes in grey scale shades. The ages in Figure 3 indicate some of the IRHs in the radargrams that correspond to a reported match points between EGRIP, NGRIP and NEEM ice cores by Mojtabavi and others (2020). The timescale was transferred from the ice cores to several key IRHs by synchronization of the synthetic and RES radargrams, following the procedures of Winter and others (2017, 2019). After the depth-to-TWT conversion of the DEP data, we mute certain conductivity and permittivity peaks from the DEP data to identify their precise depth in synthetic radargrams. We then use the depth-age relation to transfer age to the IRH depths from the Greenland Ice Core Chronology 2005 (GICC05) timescale for the EGRIP, NEEM and NGRIP2 ice cores (Mojtabavi and others, 2020; Rasmussen and others, 2013). The matched IRHs of synthetic and real radargrams that are sensitive to muting conductivity peaks in the DEP record are listed in Table 3 . In the following paragraphs we describe the key features of the comparison for each site separately.

\section{EGRIP}

The two deepest peaks in the RES data at 22.5 and $24.0 \mu$ s TWT, just at the bottom of the available ice core and $\sim 8 \mu$ SWT above the bedrock reflection at the EGRIP drill site, are highlighted in Figure 2 and can be unambiguously matched between data and model. In the interval between $\sim 4$ and $16 \mu$ sWT, a number of other reflections can be matched. The reflections at 5, 10 and $15 \mu \mathrm{s}$ TWT are other examples of the upper part of EGRIP drill site, which appear to have their representation in the synthetic trace. The climatic transition from Holocene to the last glacial (Fig. 3) is characterized by a change from darker to lighter shades of grey ( $\sim 15 \mu$ s TWT in EGRIP). This is a widespread signal in radar sections all over Greenland (e.g. MacGregor and others, 2015).

The specific ice-stream flow regime of the NEGIS motivates us to investigate the potential effects of anisotropy in the RES data. We define two reference depths: a shallow one at $s_{0}=$ $190.415 \mathrm{~m}$, and a deep one at $849.98 \mathrm{~m}(9.9500 \mu \mathrm{s})$ to more easily focus on the deeper part of the ice. In the upper and lower halves of Table 4 (Appendix B 'Anisotropy') the anisotropy is shown which was calculated with respect to the upper and lower reference depth, respectively. It is evident that the anisotropy derived from the time difference of reflections in the along- and crossflow profiles, originating from the same physical reflector, is consistently smaller in the upper $850 \mathrm{~m}$ of the ice stream than below and $\varepsilon_{\perp}^{\prime}-\varepsilon_{\|}^{\prime}$ is always positive.

\section{NEEM}

At NEEM, the ice core was drilled to the bedrock and the DEP record terminates a few meters above the bedrock. In the first and second panel of Figure 2, a number of distinct reflectors match between measured and synthetic traces. In some sections, the synthetic peaks are very close to each other (brown arrows in Fig. 2), for example, around 0.7 and $2.7 \mu$ sWT. Due to the different time resolution of modelled and measured data, it is difficult to unambiguously assign conductivity peaks to the corresponding radar reflections. Eisen and others (2006) and Winter and others (2017) show that sometimes several peaks need to be muted from DEP data in order to remove a single reflection peak in model results, indicating that a particular reflection can be the result of interferences of DEP peaks. It has to be noted that the RES reflector at $22.2 \mu \mathrm{s}$ is not reproduced with the same relative amplitude in our model results (purple arrow in Fig. 2), indicating that this reflection might be caused by a different process than conductivity. This is further investigated in the Discussion section. We highlight several distinct reflections from the NEEM drill site with orange double arrow indicators (Fig. 3).

\section{NGRIP2}

We highlight 21 IRHs in NGRIP2 (Fig. 2) which can be matched between the synthetic trace and RES data set. The events match very well below $18 \mu$ sWT (Figs 2, 3), not only in depth, but also in the characteristic shape of the signal. We also have clearly matched IRHs (green double arrow) within the top part of the ice column, as seen in Figure 3. Some reflections, e.g. the signal around $31 \mu \mathrm{s}$, can be better identified and matched in the $Z$-scope records (Fig. 3) than in the single-trace A-scopes (Fig. 2).

\section{Discussion}

\section{Origin of radar IRH}

In our results, we showed that a number of reflections are reproduced by forward modelling, based on the electric conductivity of the ice core DEP signal. This is in accordance with previous studies (Hempel and others, 2000; Miners and others, 2002; Eisen and others, 2006) which have shown that conductivity can explain the majority of reflections in the radar signals in ice sheets. The COF of the ice, which is stronger at the base of the ice sheets, also has an influence on the radar wave propagation as well as on 


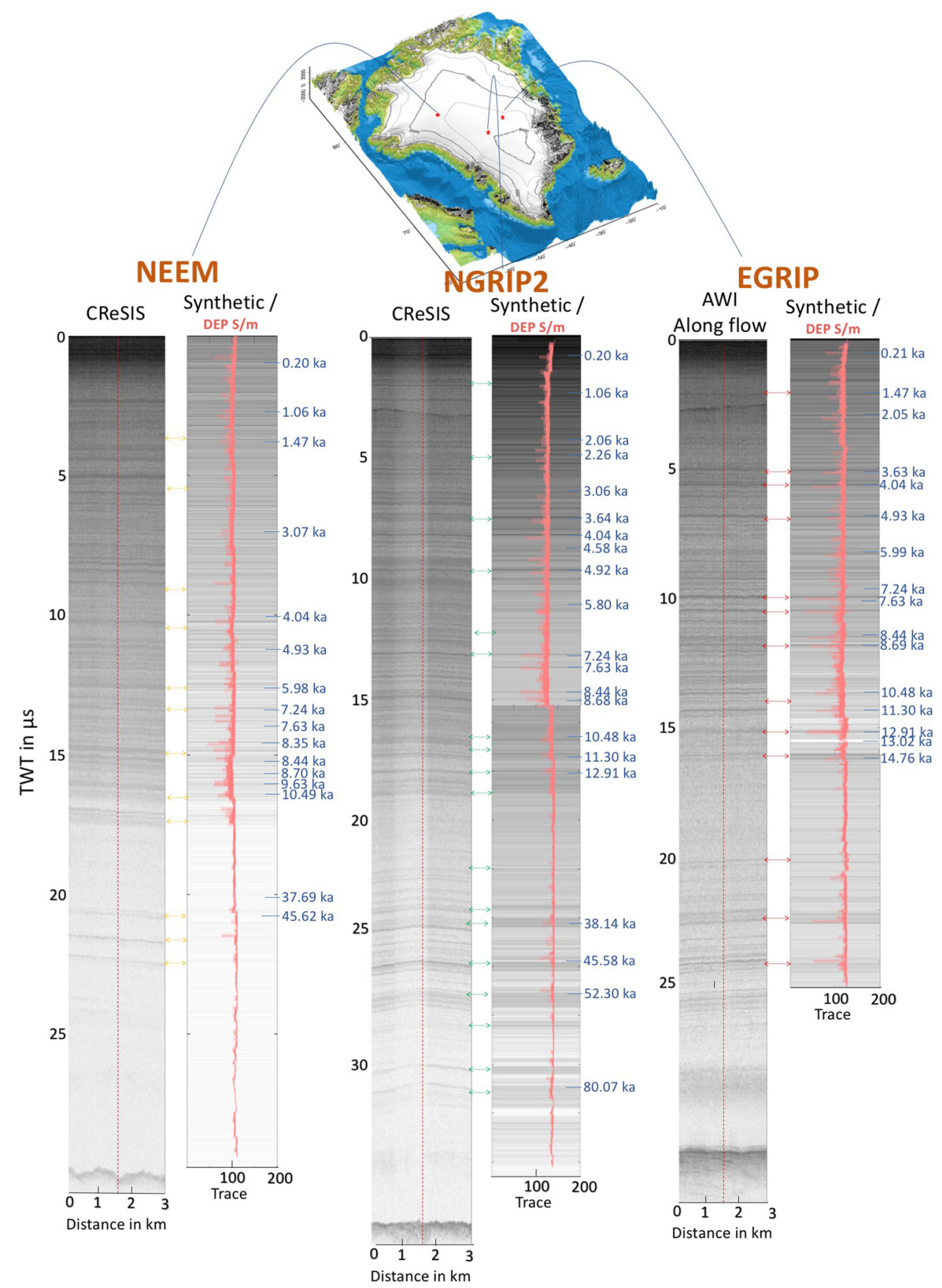

Fig. 3. Z-scopes for synthetic and RES data at the NEEM, NGRIP2 and EGRIP ice cores. The surface reflection of each measured radargram is shifted to time zero. The coloured double arrows indicate the corresponding reflections between synthetic and RES radargrams. The vertical red dashed lines mark the positions of the traces of Figure 2, which correspond to the location of the traces closest to the the borehole locations. The age-depth scale (Rasmussen and others, 2013; Mojtabavi and others, 2020) is based on IRHs in Table 3. The Greenland map is based on the GEBCO (2014) data.

reflectivity in ice (Eisen and others, 2007). In several occasions, such changes seem to coincide with changes of the ice's impurity content, e.g. caused by volcanic impurities or fundamental changes of the climate system (e.g. glacial transitions and DO events), which are closely related to the conductivity changes (Fujita and Mae, 1994; Fujita and others, 1999; Hempel and others, 2000; Eisen and others, 2006). As an example, at $17 \mu$ s TWT (Fig. 3, NEEM), we can detect the climatic transition in both modelled and measured radargrams. This transition manifests itself in lower overall backscatter in the glacial period (below $17 \mu$ s TWT), caused by higher alkalinity due to increased dust content (similar to the NGRIP, Ruth and others (2003)), which in turn at least partly neutralizing acids, which are responsible for the electric conductivity. We identify a strong reflection at $\sim 4.49 \mu$ s TWT, i.e. around
$390 \mathrm{~m}$ in NGRIP2, in particular in the Z-scopes (Fig. 3) most likely caused by a historical and massive eruption of Alaska's Okmok volcano around 2543 a b2k (McConnell and others, 2020).

To underline the direct connection between ice-core dielectric properties and radar signals further, but also to illustrate the direction-dependent depth of IRHs in radargrams, Figure 4 shows a modelled radargram based on EGRIP DEP data, and two RES profiles oriented along and across-flow direction (see cartoon in Fig. 4). Conductivity changes can explain most of the IRHs at the EGRIP drill site. It also shows an effect of the flow velocity changes in the shear margins of NEGIS, which causes folding (Robert and others, 1993) (Fig. 4) in the profile oriented across ice-flow. The folding is apparent in the stratigraphy by strongly inclined reflections, which have a much larger 


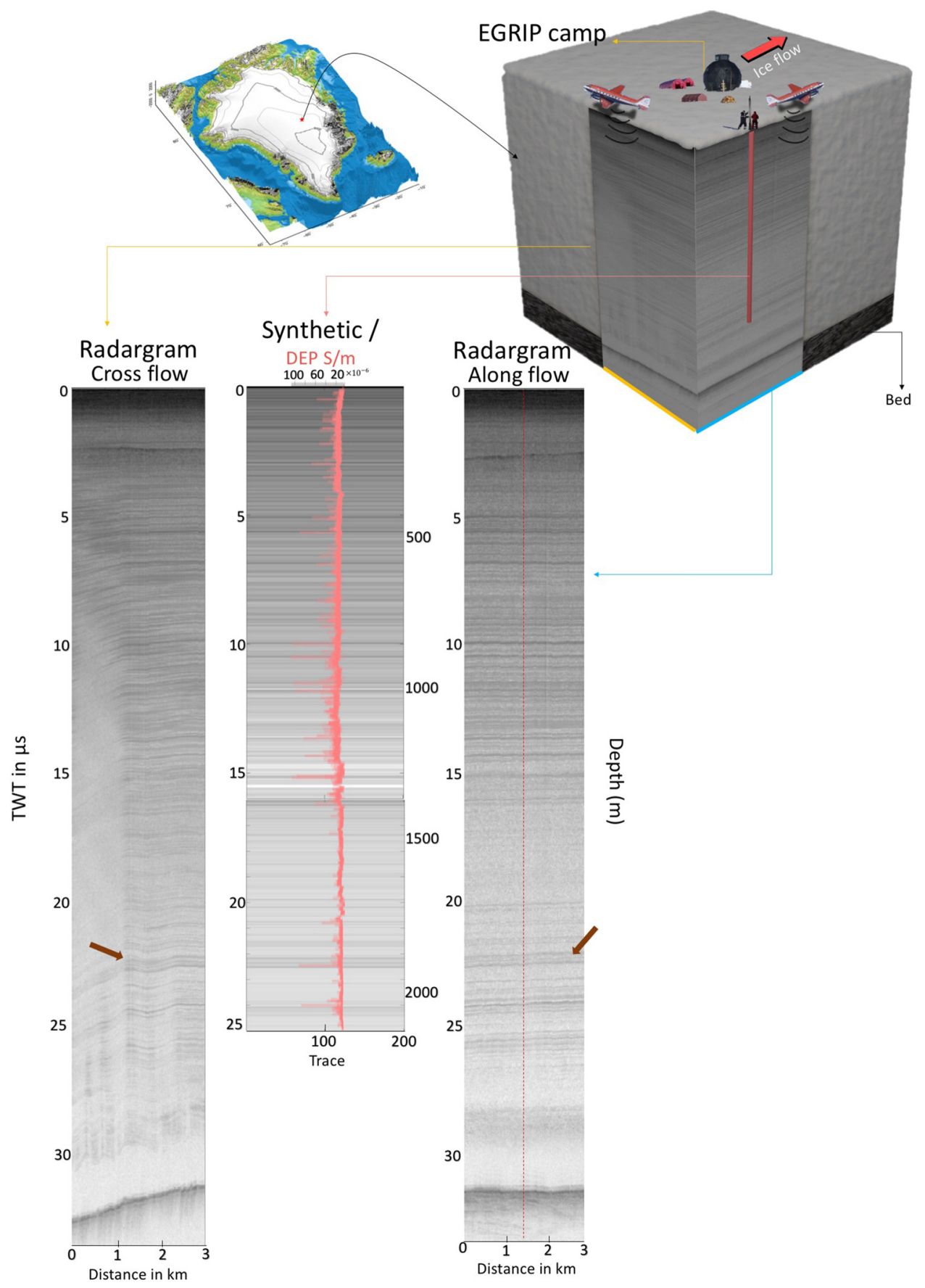

Fig. 4. Z-scopes of synthetic and RES data sets of the EGRIP ice core location. The vertical red dashed line shows the position of the trace of Figure 2. The coloured arrows show IRHs that are described in detail in the Discussion section. The Greenland map is based on the GEBCO (2014) data.

spatial gradient than along-flow which results in weak signals (brown arrows in Fig. 4). In the case that only a single radar profile near a core site is available, such variations in the radar signatures (see RES cross-flow profile in Fig. 4), which depend on the direction of the profile, have to be considered when matching radar observations and ice-core data.

Previous studies (Dahl-Jensen and others, 2013; Eichler and others, 2013; Montagnat and others, 2014; Li and others, 2018) showed that the NEEM core is a folded core with a strong change in the COF at $2200 \mathrm{~m}$ depth (Fig. 5). As mentioned above, we identify a strong reflection at $\sim 22.2 \mu$ s i.e. around $1889 \mathrm{~m}$ depth that is only reproduced with a small signal in our synthetic result. The faint signals in the synthetic trace indicate that there is a small signal linked to the conductivity in the DEP data. The observed large peak at $22.2 \mu$ s in the RES data could indicate that the source of the IRH is not only due to a change in conductivity, as we observed it in the DEP data. At that depth, another possibility for the source of the IRH is the sudden change of COF. The change of eigenvalues and fabric images ( $c$-axes) (Eichler and others, 2013) correspond to this depth at $22.2 \mu \mathrm{s}$ in Figure 5. Our interpretation is therefore similar to the one by Eisen and others (2007), who also indicated that a radar reflection at $2040 \mathrm{~m}$ depth at the EDML drill site in Antarctica resulted from changes in crystal-orientation fabric.

At two ice-core sites, we have deep sections without any significant reflections: at NGRIP2 below $30 \mu \mathrm{s}$ TWT, and at NEEM below $25 \mu$ sWT. In Antarctica, the deepest part of the ice sheet is described as an echo-free zone (EFZ) (e.g. Fujita and others, 1999; Drews and others, 2009; Winter and others, 2017) which is characterized by a sudden drop of returned 


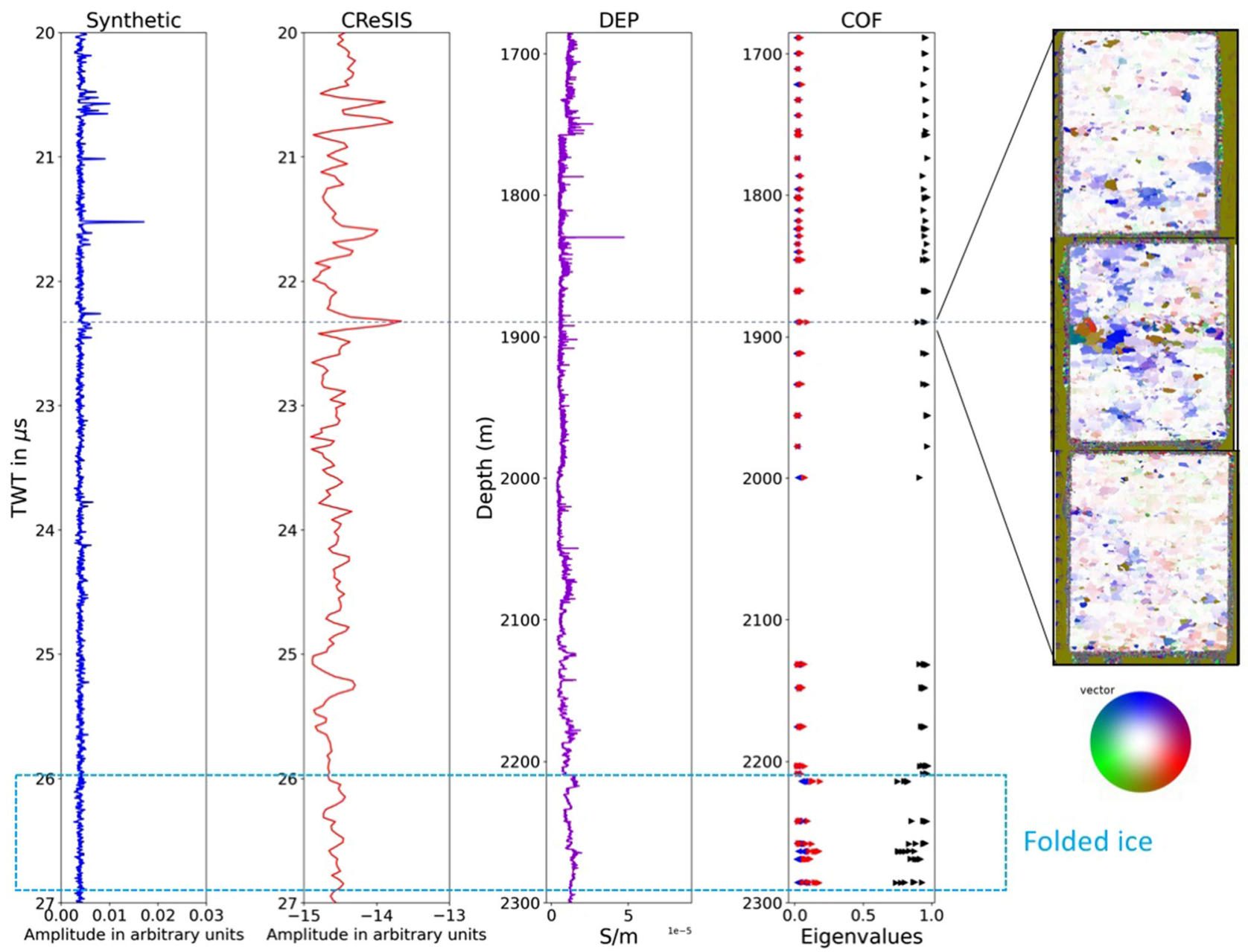

Fig. 5. Example of the reflection for potential crystal orientation fabric (COF) at the NEEM drill site. From left to right: DEP data (conductivity); A-scopes for traces of the synthetic (blue) and measured (red) traces at NEEM of Figure 2; fabric data along the NEEM ice core (Eichler and others, 2013; Montagnat and others, 2014), orientation-tensor eigenvalues ( $\lambda_{1}$ : black triangle, $\lambda_{2}$ : red triangle, $\lambda_{3}$ : blue triangle); segmentation of the fabric image (Eichler and others, 2013; Montagnat and others, 2014) with colour-coded $c$-axes orientations of the reflection section; dashed horizontal line connect the RES reflector with the depth of changes in COF ( $1900 \mathrm{~m}$ depth). A sudden change in eigenvalues of the distribution of $c$-axes and segmentation of the fabric image show the IRH observed in RES at $\sim 1900 \mathrm{~m}$ depth could be caused by slight changes in COF.

power in the RES data. A study by Drews and others (2009) shows disappearance of continuous IRHs in deeper sections of the Antarctic EDML drill site, related to changing physical properties. As the NEEM ice core has a continuous DEP record down to the bedrock (Dahl-Jensen and others, 2013) we can conclude for the Greenland sites that the origin of these low-backscatter zones is rather related to low variability in dielectric properties and lower sensitivity of the radar system in use.

\section{Possible across-flow concentrated fabric at EGRIP}

We analysed the differences in the traveltime of unambiguously identifiable reflections in two perpendicular profiles near EGRIP, one along-flow, the other cross-flow. We translated these into the bulk anisotropy of permittivity (Table 4 in Appendix B 'Anisotropy'), which is inherently related to the COF. Evidently, below a depth of $980 \mathrm{~m}$ down to our last matching IRH at $2041 \mathrm{~m}$ depth, the permittivity shows the strongest possible difference between cross and along flow. However, as also shown in Table 3, the relative error $\left(\sigma\left(\varepsilon_{\perp}-\varepsilon_{\|}\right)\right) /\left(\varepsilon_{\perp}-\varepsilon_{\|}\right)$ ranges between 30 and $70 \%$, with an average of $56 \%$. This error comes along with uncertainties in TWT determination and is too large to make strong quantitative conclusions about the type of fabric (e.g. horizontally transverse isotropic single maximum versus strongly aligned girdle), its exact orientation or its evolution with depth. Nevertheless, our analysis is robust enough to make two statements: first, the fabric shows a strong anisotropy in the horizontal plane, indicating at least a girdle fabric; second, given that the permittivity cross-flow is larger than the permittivity along flow, this implies that the $c$-axes are concentrated in the plane perpendicular to the flow direction. In a flow regime with uniaxial extension, a fabric with $c$-axes concentrated in the plane perpendicular to extension direction develops. Our interpretation of the RES-based analysis of anisotropy is in agreement with the finding observed in the EGRIP ice core (Westhoff and others, 2021), who place the $c$-axes in the regional reference frame in a plane roughly northwest-southeast. Both results are supporting a fabric which is consistent with horizontal extension in flow direction at the EGRIP site. Methodologically, it is attractive to apply this approach on a routine basis to those regions where several crossing radar profiles are available in order to determine the horizontal anisotropy of the bulk fabric. Increasing the number of crossover points in such an analysis, as for instance available for the EGRIP-NOR-2018 survey, would also reduce the overall influence of the relatively large uncertainty from deducing horizontal anisotropy from single IRHs only. As ice-stream dynamics induces particular fabric patterns, the application of our approach described here as well as 
other approaches (e.g. Young and others, 2021) have the potential to eventually a more consistent way to characterize ice stream properties on a regional scale and not only at point locations.

\section{Age stratigraphy}

By linking the dated events from DEP records at the locations of three deep ice cores to reflections in airborne RES data, we are able to provide a more accurate dating of the radar IRHs, which can then be extended along the radar lines over large parts of northern Greenland (e.g. MacGregor and others, 2015). Using our forward modelling approach, the depth uncertainties of the IRHs are reduced compared to the common TWT-to-depth conversion with a constant electromagnetic wave speed approach. With the forward DEP modelling approach, the depth uncertainties are related to the DEP measurements and the width of the reflection-causing conductivity peaks (Winter and others, 2019). Our age stratigraphy with a direct connection of different deep ice cores can be used to better understand internal processes (i.e. ice deformation) in the Greenland Ice Sheet. It could also provide an improved assessment of age accuracy in northern Greenland, as the one provided by MacGregor and others (2015) for the Greenland Ice Sheet.

\section{Conclusions}

We have characterized the origin of the IRHs inside the Greenland Ice Sheet by radar forward modelling. In order to understand physical processes that cause the IRH and identify ages for the reflectors causing the layers, we rely on the airborne radar measurements and modelling of synthetic radar traces that were fed by conductivity and permittivity data from EGRIP, NEEM and NGRIP2 ice cores in Greenland. Our results show excellent agreement for most of the IRHs between the synthetic results and the RES measurements. From the comparison between the measured and modelled traces, we conclude that conductivity peaks are responsible for most radar IRHs. Overall, the modelling results demonstrate that the internal reflections of the ice sheet are due mostly to conductivity changes. In some cases, however, conductivity plays only a minor role and the dominant reflection mechanisms seem to be anisotropic backscatter at interfaces where the bulk fabric changes. IRHs in the observed radargrams have been dated by means of the presented sensitivity studies with the DEP record using the GICC05 time scale. For EGRIP our comparison of along and cross-flow wave propagation speeds suggests a concentration of the $c$-axes in a girdle perpendicular to the flow direction (below 980 meters). Based on this analysis, we are able to orient the observed fabric in the ice core in the absolute reference frame of the ice sheet and support the discussed flow regime of uniaxial extension. This approach could be extended to map the horizontal anisotropy in larger regions where numerous radar lines crossovers are available. Given that our thorough understanding of complex ice-stream dynamics is a key requirement to improve paleo-reconstruction and prognoses of future ice-stream behaviour, especially for sealevel projections. Unfortunately, the current horizontal anisotropy does not represent into ice-sheet models, while anisotropic ice can enhance the speed of ice flow (Glen, 1958). We recommend extending our approach to more thoroughly map horizontal anisotropy in regions where numerous crossing of radar lines are available and plan future surveys accordingly.

\section{Data availability}

Specific conductivity measured with the dielectric profiling (DEP) technique on the EGRIP ice core, 1383.84-2122.445 m depth (https://doi.pangaea. de/10.1594/PANGAEA.922285).
Permittivity measured with the dielectric profiling (DEP) technique on the EGRIP ice core, 1383.84-2122.445 m depth (https://doi.pangaea.de/10. 1594/PANGAEA.922299).

Specific conductivity measured with the dielectric profiling (DEP) technique on the NEEM ice core (1493.297-1757.310 m depth) (https://doi.pangaea. de/10.1594/PANGAEA.922303).

Permittivity measured with the dielectric profiling (DEP) technique on the NEEM ice core (1493.297-1757.310 m depth) (https://doi.pangaea.de/10. 1594/PANGAEA.922305).

Specific conductivity measured with the dielectric profiling (DEP) technique on the NGRIP2 ice core (down to $1298.555 \mathrm{~m}$ depth) (https://doi.pangaea.de/10.1594/PANGAEA.922306).

Permittivity measured with the dielectric profiling (DEP) technique on the NGRIP2 ice core (down to $1298.555 \mathrm{~m}$ depth) (https://doi.pangaea.de/10. 1594/PANGAEA.922308).

AWI ultra-wideband (UWB) airborne radar data around the EastGRIP drill site at the onset region of the Northeast Greenland Ice Stream (https:// doi.pangaea.de/10.1594/PANGAEA.932334).

Acknowledgements. We thank three anonymous reviewers for fruitful comments that improved the paper a lot. EGRIP is directed and organized by the Centre for Ice and Climate at the Niels Bohr Institute, University of Copenhagen. It is supported by funding agencies and institutions in Denmark (A. P. Møller Foundation, University of Copenhagen), USA (US National Science Foundation, Office of Polar Programs), Germany (Alfred Wegener Institute, Helmholtz Centre for Polar and Marine Research), Japan (National Institute of Polar Research and Arctic Challenge for Sustainability), Norway (University of Bergen and Bergen Research Foundation), Switzerland (Swiss National Science Foundation), France (French Polar Institute Paul-Emile Victor, Institute for Geosciences and Environmental research) and China (Chinese Academy of Sciences and Beijing Normal University). We acknowledge the use of data from CReSIS generated with support from the University of Kansas, NASA Operation IceBridge grant NNX16AH54G, NSF grants ACI-1443054, OPP-1739003, and IIS-1838230, Lilly Endowment Incorporated, and Indiana METACyt Initiative. Dorthe Dahl-Jensen acknowledges Villum Investigator IceFlow (grant nr16572). We thank Sepp Kipfstuhl, Nanna B. Karlsson, Sergio Henrique Faria, Vasileios Gkinis and Helle Astrid Kjær for helping to measure DEP data during 2017 and 2018 seasons in EGRIP camp. We thank Eliza Cook, Tobias Erhardt and all people involved in ice-core processing, drilling and logistics in the field. We thank Tobias Binder, who helped with the radar measurements and the crew of the aircraft Polar6 and system engineer Lukas Kandora during the AWI flight campaign 2018. We thank Sepp Kipfstuhl for assistance with the NGRIP2 DEP data.

Author contributions. SM wrote the manuscript and conducted the main part of analysis; figures were created by SM; synthetic radar modelling was done by SM using the emice model implemented by OE; DEP measurements in the field were done by SM; DEP data processing was done by SM and FW; selection and compilation of radar data sets were done by SM, SF; AWI UWB radar processing was done by SF, DS; AWI (Polar6 aircraft, 2018) measurements in the field were done by DJ, JP; EGRIP anisotropy analysis was done by SM, FW; NEEM COF data processing was done by IW and JE; data interpretations were done by SM, OE, FW; all authors contributed to improving the writing and discussing of paper.

\section{References}

Arcone SA, Spikes VB, Hamilton GS and Mayewski PA (2004) Stratigraphic continuity in $400 \mathrm{MHz}$ short-pulse radar profiles of firn in West Antarctica. Annals of Glaciology 39, 195-200. doi: 10.3189/172756404781813925

Cavitte MG and 7 others (2016) Deep radiostratigraphy of the East Antarctic plateau: connecting the Dome $\mathrm{c}$ and Vostok ice core sites. Journal of Glaciology 62(232), 323-334. doi: 10.1017/jog.2016.11

Cavitte MGP and 7 others (2018) Accumulation patterns around Dome c, East Antarctica, in the last $73 \mathrm{kyr}$. The Cryosphere 12(4), 1401-1414. doi: 10.5194/tc-12-1401-2018

Christianson K and 7 others (2014) Dilatant till facilitates ice-stream flow in Northeast Greenland. Earth and Planetary Science Letters 401, 57-69. doi: 10.1016/j.epsl.2014.05.060 
CReSIS (2016) Radar Depth Sounder Data. Lawrence, Kansas, USA: Digital Media. http://data.cresis.ku.edu/.

Dahl-Jensen D and 10 others (2013) Eemian interglacial reconstructed from a Greenland folded ice core. Nature 493(7433), 489-494. doi: 10.1038/ nature11789

Dall J (2010) Ice sheet anisotropy measured with polarimetric ice sounding radar. 2010 IEEE International Geoscience and Remote Sensing Symposium, pp. 2507-2510. IEEE. https://orbit.dtu.dk/en/publications/icesheet-anisotropy-measured-with-polarimetric-ice-sounding-rada.

Drews R and 7 others (2009) Layer disturbances and the radio-echo free zone in ice sheets. The Cryosphere 3(2), 195-203. doi: 10.5194/tc-3-195-2009

Edwards TL and 83 others (2021) Projected land ice contributions to twenty-first-century sea level rise. Nature 593(7857), 74-82. doi: 10.1038 s41586-021-03302-y

Eichler J, Weikusat I and Kipfstuhl S (2013) (Fig. 21) Orientation-tensor eigenvalues along the NEEM ice core. PANGAEA (doi: 10.1594/PANGAEA 838059), in supplement to: Eichler, Jan (2013): C-axis analysis of the NEEM ice core - an approach based on Digital Image Processing. Diploma Thesis, Fachbereich Physik, Freie Universität Berlin, 73 pp, hdl:10013/ epic.41621.d001.

Eisen O, Hamann I, Kipfstuhl S, Steinhage D and Wilhelms F (2007) Direct evidence for continuous radar reflector originating from changes in crystal-orientation fabric. The Cryosphere 1(1), 1-10. doi: 10.5194/ tc-1-1-2007

Eisen O, Nixdorf U, Wilhelms F and Miller H (2004) Age estimates of isochronous reflection horizons by combining ice core, survey, and synthetic radar data. Journal of Geophysical Research 109, B04106. doi: 10.1029/ 2003JB002858.

Eisen O, Wilhelms F, Nixdorf $\mathbf{U}$ and Miller $\mathbf{H}$ (2003) Revealing the nature of radar reflections in ice: DEP-based FDTD forward modeling. Geophysical Research Letters 30(5), 1218. doi: 10.1029/2002GL016403.

Eisen O, Wilhelms F, Steinhage D and Schwander J (2006) Improved method to determine radio-echo sounding reflector depths from ice-core profiles of permittivity and conductivity. Journal of Glaciology 52(177), 299-310. doi: 10.3189/172756506781828674

Fahnestock MA and 5 others (2001) Ice-stream-related patterns of ice flow in the interior of Northeast Greenland. Journal of Geophysical Research: Atmospheres 106(D24), 34035-34045. doi: 10.1029/2001JD900194

Fahnestock M, Bindschadler R, Kwok R and Jezek K (1993) Greenland ice sheet surface properties and ice dynamics from ERS-1 SAR imagery. Science 262(5139), 1530-1534. doi: 10.1126/science.262.5139.1530

Faria SH, Weikusat I and Azuma N (2014) The microstructure of polar ice. Part I: highlights from ice core research. Journal of Structural Geology 61, 220. doi: 10.1016/j.jsg.2013.09.010

Franke S and 6 others (2020a) Complex basal conditions and their influence on ice flow at the onset of the Northeast Greenland Ice Stream. Journal of Geophysical Research: Earth Surface 126, e2020JF005689. doi: 10.1029/ 2020JF005689.

Franke S and 7 others (2020b) Bed topography and subglacial landforms in the onset region of the Northeast Greenland Ice Stream. Annals of Glaciology 61(81), 143-153. doi: 10.1017/aog.2020.12

Franke S and 12 others (2021) Airborne ultra-wideband radar sounding over the shear margins and along flow lines at the onset region of the Northeast Greenland Ice Stream. Earth System Science Data Discussions 2021, 1-24. doi: 10.5194/essd-2021-91

Fujita S and 6 others (1999) Nature of radio echo layering in the Antarctic ice sheet detected by a two-frequency experiment. Journal of Geophysical Research: Solid Earth 104(B6), 13013-13024. doi: 10.1029/1999JB900034

Fujita S and Mae S (1994) Causes and nature of ice-sheet radio-echo internal reflections estimated from the dielectric properties of ice. Annals of Glaciology 20, 80-86. doi: 10.3189/1994AoG20-1-80-86

Fujita S, Mae S and Matsuoka T (1993) Dielectric anisotropy in ice ih at 9.7 GHz. Annals of Glaciology 17, 276-280. doi: 10.3189/S0260305500012969

GEBCO (2014) General Bathymetric Chart of the Oceans (GEBCO), https://www. gebco.net/data_and_products/gridded_bathymetry_data/version_20141103/.

Glen J (1958) The flow law of ice: a discussion of the assumptions made in glacier theory, their experimental foundations and consequences. IASH Publ 47(171), e183.

Gusmeroli A, Pettit EC, Kennedy JH and Ritz C (2012) The crystal fabric of ice from full-waveform borehole sonic logging. Journal of Geophysical Research: Earth Surface 117, F03021. doi: 10.1029/2012JF002343.
Hale R and 11 others (2016) Multi-channel ultra-wideband radar sounder and imager. 2016 IEEE International Geoscience and Remote Sensing Symposium (IGARSS), Beijing, China, pp. 2112-2115. IEEE.

Hempel L, Thyssen F, Gundestrup N, Clausen HB and Miller H (2000) A comparison of radio-echo sounding data and electrical conductivity of the grip ice core. Journal of Glaciology 46(154), 369-374. doi: 10.3189/ 172756500781833070

Hvidberg CS and 10 others (2020) Surface velocity of the Northeast Greenland Ice Stream (NEGIS): assessment of interior velocities derived from satellite data by GPS. The Cryosphere 14(10), 3487-3502. doi: 10 . 5194/tc-14-3487-2020

Joughin I, Smith BE and Howat IM (2018) A complete map of Greenland ice velocity derived from satellite data collected over 20 years. Journal of Glaciology 64(243), 1-11. doi: 10.1017/jog.2017.73

Karlsson NB and 9 others (2016) Accumulation rates during 1311-2011 CE in North-Central Greenland derived from air-borne radar data. Frontiers in Earth Science 4, 97. doi: 10.3389/feart.2016.00097

Kjær KH and 21 others (2018) A large impact crater beneath Hiawatha Glacier in Northwest Greenland. Science Advances 4(11), eaar8173. doi: 10.1126/sciadv.aar8173.

Larsen NK and 7 others (2018) Instability of the Northeast Greenland Ice Stream over the last 45,000 years. Nature Communications 9(1), 1872. doi: 10.1038/s41467-018-04312-7

Li J and 8 others (2018) Multi-channel and multi-polarization radar measurements around the NEEM site. The Cryosphere 12(8), 2689-2705. doi: 10 5194/tc-12-2689-2018

Llorens MG and 6 others (2016) Dynamic recrystallisation of ice aggregates during co-axial viscoplastic deformation: a numerical approach. Journal of Glaciology 62(232), 359-377. doi: 10.1017/jog.2016.28

MacGregor JA and 9 others (2015) Radiostratigraphy and age structure of the Greenland Ice Sheet. Journal of Geophysical Research: Earth Surface 120(2), 212-241. doi: 10.1002/2014JF003215

Matsuoka T, Fujita S, Morishima S and Mae S (1997) Precise measurement of dielectric anisotropy in ice Ih at $39 \mathrm{GHz}$. Journal of Applied Physics 81(5), 2344-2348. doi: 10.1063/1.364238

McConnell JR and 19 others (2020) Extreme climate after massive eruption of Alaska's Okmok volcano in 43 BCE and effects on the late Roman Republic and Ptolemaic Kingdom. Proceedings of the National Academy of Sciences 117(27), 15443-15449. doi: 10.1073/pnas.2002722117

Miners WD, Wolff EW, Moore JC, Jacobel R and Hempel L (2002) Modeling the radio echo reflections inside the ice sheet at Summit, Greenland. Journal of Geophysical Research: Solid Earth 107(B8), EPM 6-1-EPM 6-11. doi: 10.1029/2001JB000535.

Mojtabavi S and 19 others (2020) A first chronology for the East Greenland Ice-core Project (EGRIP) over the Holocene and last glacial termination. Climate of the Past 16(6), 2359-2380. doi: 10.5194/cp-16-2359-2020

Montagnat $\mathbf{M}$ and 9 others (2014) Fabric along the NEEM ice core, Greenland, and its comparison with GRIP and NGRIP ice cores. The Cryosphere 8(4), 1129-1138. doi: 10.5194/tc-8-1129-2014

Moore J and Paren J (1987) A new technique for dielectric logging of Antarctic ice cores. Journal de Physique Colloques 48(C1), C1-155-C1160. doi: 10.1051/jphyscol:1987123.

Paren JG and Robin GdQ (1975) Internal reflections in polar ice sheets. Journal of Glaciology 14(71), 251-259. doi: 10.3189/S0022143000021730

Qi C and 8 others (2019) Crystallographic preferred orientations of ice deformed in direct-shear experiments at low temperatures. The Cryosphere 13(1), 351-371. doi: 10.5194/tc-13-351-2019

Rasmussen SO and 23 others (2013) A first chronology for the North Greenland Eemian Ice Drilling (NEEM) ice core. Climate of the Past 9(6), 2713-2730. doi: 10.5194/cp-9-2713-2013

Robert WJ, Anthony MG, David LG, Steven MH and David LW (1993) Interpretation of radar-detected internal layer folding in West Antarctic ice streams. Journal of Glaciology 39(133), 528-537. doi: 10.3189/ S0022143000016427

Rodriguez-Morales F and 17 others (2014) Advanced multifrequency radar instrumentation for polar research. IEEE Transactions on Geoscience and Remote Sensing 52(5), 2824-2842. doi: 10.1109/TGRS.2013.2266415

Ruth U, Wagenbach D, Steffensen JP and Bigler M (2003) Continuous record of microparticle concentration and size distribution in the central Greenland NGRIP ice core during the last glacial period. Journal of Geophysical Research: Atmospheres 108(D3), 4098. doi: 10.1029/2002JD002376. 
Schroeder DM and 9 others (2019) Multidecadal observations of the Antarctic ice sheet from restored analog radar records. Proceedings of the National Academy of Sciences 116(38), 18867-18873. doi: 10.1073/pnas.1821646116

Shepherd A and 89 others (2019) Mass balance of the Greenland Ice Sheet from 1992 to 2018. Nature 579(7798), 233-239. doi: 10.1038/s41586-019-1855-2

Siegert MJ, Hodgkinst R and Dowdeswell JA (1998) Internal radio-echo layering at Vostok station, Antarctica, as an independent stratigraphie control on the ice-core record. Annals of Glaciology 27, 360-364. doi: 10.3189/ 1998AoG27-1-360-364

Stocker T and 33 others (2013) Technical Summary, Climate Change 2013: The Physical Science Basis. Contribution of Working Group I to the Fifth Assessment Report of the Intergovernmental Panel on Climate Change, book section TS, 33-115. Cambridge, United Kingdom and New York, NY, USA: Cambridge University Press. ISBN 978-1-107-66182-0 (doi: 10. 1017/CBO9781107415324.005).

Tapley BD and 20 others (2019) Contributions of grace to understanding climate change. Nature Climate Change 9(5), 358-369. doi: 10.1038/ s41558-019-0456-2

Thorsteinsson T, Waddington ED, Taylor KC, Alley RB and Blankenship DD (1999) Strain-rate enhancement at dye 3, Greenland. Journal of Glaciology 45(150), 338-345. doi: 10.3189/S0022143000001830

Urbini S and 6 others (2008) Historical behaviour of Dome C and Talos Dome (East Antarctica) as investigated by snow accumulation and ice velocity measurements. Global and Planetary Change 60(3), 576-588. doi: 10.1016/j.gloplacha.2007.08.002.

Vallelonga $P$ and 22 others (2014) Initial results from geophysical surveys and shallow coring of the Northeast Greenland Ice Stream (NEGIS). The Cryosphere 8(4), 1275-1287. doi: 10.5194/tc-8-1275-2014

Westhoff $\mathbf{J}$ and 8 others (2021) A stratigraphy-based method for reconstructing ice core orientation. Annals of Glaciology 62(85-86), 191-202. doi: 10. 1017/aog.2020.76

Wilhelms F (1996) Leitfähigkeits- und Dichtemessung an Eisbohrkernen = Measuring the conductivity and density of ice cores, Berichte zur Polarforschung (Reports on Polar Research), Bremerhaven, Alfred Wegener Institute for Polar and Marine Research, vol. 191. (doi: 10.2312/ BzP_0191_1996xxxx).

Wilhelms F (2005) Explaining the dielectric properties of firn as a density-and-conductivity mixed permittivity (DECOMP). Geophysical Research Letters 32, L16501. doi: 10.1029/2005GL022808.

Wilhelms F, Kipfstuhl J, Miller H, Heinloth K and Firestone J (1998) Precise dielectric profiling of ice cores: a new device with improved guarding and its theory. Journal of Glaciology 44(146), 171-174. doi: 10.3189/S002214300000246X

Winter A and 9 others (2017) Comparison of measurements from different radioecho sounding systems and synchronization with the ice core at Dome c, Antarctica. The Cryosphere 11(1), 653-668. doi: 10.5194/tc-11-653-2017

Winter A, Steinhage D, Creyts TT, Kleiner T and Eisen O (2019) Age stratigraphy in the east Antarctic ice sheet inferred from radio-echo sounding horizons. Earth System Science Data 11(3), 1069-1081. doi: 10.5194/essd-11-1069-2019

Wolff EW, Chappellaz J, Blunier T, Rasmussen SO and Svensson A (2010) Millennial-scale variability during the last glacial: the ice core record. Quaternary Science Reviews 29(21), 2828-2838. doi: 10.1016/j.quascirev. 2009.10.013.

Young TJ and 6 others (2021) Inferring ice fabric from birefringence loss in airborne radargrams: application to the eastern shear margin of Thwaites Glacier, West Antarctica. Journal of Geophysical Research: Earth Surface 126(5), e2020JF006023. doi: 10.1029/2020JF006023.

\section{Appendix A. Details on the modelling of synthetic radar traces}

In order to convert the depth of DEP data to the two-way travel time (TWT) domain of the RES data, we need to determine the electromagnetic wave speed in firn and ice $c_{z}$ with the speed of light in a vacuum $c_{0}$ and the real component $\varepsilon^{\prime}$ of the complex relative dielectric permittivity, $\varepsilon^{*}$,

$$
\begin{aligned}
& c_{z}=\frac{c_{0}}{\sqrt{\varepsilon^{*}}} \approx \frac{c_{0}}{\sqrt{\varepsilon^{\prime}}}, \\
& \text { where } \\
& \varepsilon^{*}=\varepsilon^{\prime}-\mathrm{i} \varepsilon^{\prime \prime}, \\
& \text { and } \\
& \varepsilon^{\prime \prime}=\frac{\sigma}{\omega \varepsilon_{0}} .
\end{aligned}
$$

In these equations, $\varepsilon^{\prime \prime}$ is the imaginary component of the complex relative dielectric permittivity, $\sigma$ is the electric conductivity, $\varepsilon_{0}$ the dielectric permittivity of the vacuum and $\omega$ the circular frequency.

Firn in the uppermost fraction of the core is a two-phase system, being composed of ice and air. Air has a relative permittivity of 1 and basically zero conductivity (free-air conductance, as determined from an empty DEP device (Mojtabavi and others, 2020)), while the ice phase of pure glacier ice exhibits the relative permittivity $\varepsilon_{\text {ice }}$ and the conductivity $\sigma_{\text {ice }}$, which is determined by the chemical impurity load and the temperature of the ice. The complex relative dielectric permittivity $\varepsilon^{*}$ of the mixture further depends on the volume fraction of the ice phase, here being expressed as the fraction of firn density $\rho$ and pure ice density $\rho_{\text {ice }}$. The dielectric property of the firn is well described by the density and conductivity mixed permittivity (DECOMP) equation (Wilhelms, 2005):

$$
\varepsilon^{*}=\varepsilon^{\prime}-\mathrm{i} \varepsilon^{\prime \prime}=\left(\frac{\rho}{\rho_{\text {ice }}}\left(3 \sqrt{\varepsilon_{\text {ice }}^{\prime}-\mathrm{i} \frac{\sigma_{\text {ice }}}{\omega \varepsilon_{0}}}-1\right)+1\right)^{3} .
$$

Thus, we determine density and conductivity, which are frequency independent, from the DEP measurements and calculate the input to our model at the central frequency of the radar system by means of the DECOMP formula (Eisen and others, 2006).

The imaginary and real parts of the complex dielectric permittivity were measured directly in the field with a DEP bench at a frequency of $250 \mathrm{kHz}$ for all ice cores. The 'emice' model basically translates their variability with depths into reflection signatures of the impulse response of the subsurface. However, general amplitude decay with depth is not reproduced by the model as it operates in $1 \mathrm{D}$ only.

We used $0.02 \mathrm{~m}$ as model depth resolution and $0.02 \mathrm{~ns}$ for the time increment. These values are based on the stability of the numerical calculations (Eisen and others, 2006). The maximum depth varies for each ice core. We used a physical model domain equivalent to 35 and $36 \mu$ s TWT for the NEEM and NGRIP2 ice cores, respectively, to cover reflection in our model domain. The final logging depth for EGRIP is $2122.445 \mathrm{~m}$ which was drilled in field season 2019, i.e. not yet reaching bedrock. Therefore, we used $30 \mu$ s TWT to cover reflection in our synthetic model domain for the EGRIP ice core. The time ranges and the upper boundary of the model were selected sufficiently large to only cover reflections from the model boundaries based on the ice core depths, but to avoid artificial reflections from the model boundaries. Radar measurements suggest the ice thickness likely exceeds $2550 \mathrm{~m}$ (Vallelonga and others, 2014). Due to the integration over kilometres, the average dielectric permittivity for a depth interval may be determined even more precisely from the radar sounding than the estimated 1-2\% error of the DEP measurement (Wilhelms and others, 1998; Wilhelms, 2005; Mojtabavi and others, 2020). For sections below $100 \mathrm{~m}$ depth, we compared the synthetic traces calculated with varied real part of permittivity $(3.15,3.16,3.17,3.18$ and 3.19$)$ with observational radar traces TWT to find the best electromagnetic wave speed $c_{z}$ which results in the best match or synthetic and observed radar reflections, where $c_{z}$ and $\varepsilon^{\prime}$ are closely related through Eqn (A.1). The real permittivity of the DEP record varies within the estimated 1-2\% error. Apart from this methodological limitation of DEP, the permittivity offset along the symmetry axis of an ice crystal and perpendicular to it is close to $1 \%$ as well (Fujita and others, 1993). Site-dependent evolution of the crystal orientation fabric (COF) together with the lacking knowledge about the orientation of the cores (Westhoff and others, 2021), may also explain the observed variation on the permittivity records' real part. The correspondence of modelled and measured radar-traces is improved when replacing the measured dielectric permittivity's real part with a fixed average value. Therefore, an average value of permittivity can produce the reflections caused by variation in conductivity at the accurate TWT and avoids interference from reflections due to noise in the real part's record. Winter and others (2017) found a best match for a dielectric permittivity constant of 3.17 for the modelling based on the EDC ice core in Antarctica. In this study, we determined a value of 3.15 value for all ice cores which represents the best correspondence between model and measured traces for the glacial ice sections below $100 \mathrm{~m}$. 
Appendix B. Anisotropy

Table 4. The recorded depth of the DEP conductivity peaks $s$, the TWT $t_{\|}$along flow, the TWT $t_{\perp}$ cross-flow, the permittivity $\varepsilon_{\|}^{\prime}$ in polarization direction along flow, the permittivity $\varepsilon_{\perp}^{\prime}$ in polarization direction cross-flow, the difference $\varepsilon_{\perp}^{\prime}-\varepsilon_{\|}^{\prime}$ and the average permittivity $\left(\varepsilon_{\perp}^{\prime}+\varepsilon_{\|}^{\prime}\right) / 2$, the errors of the calculated permittivities $\sigma\left(\varepsilon_{\|}^{\prime}\right)$ and $\sigma\left(\varepsilon_{\perp}^{\prime}\right)$ and the error of the difference.

\begin{tabular}{|c|c|c|c|c|c|c|c|c|}
\hline$s / \mathrm{m}$ & $t_{\|} / \mu \mathrm{s}$ & $t_{\perp} / \mu \mathrm{s}$ & $\varepsilon_{\|}^{\prime}$ & $\varepsilon_{\perp}^{\prime}$ & $\varepsilon_{\perp}^{\prime}-\varepsilon_{\|}^{\prime}$ & $\frac{\varepsilon_{\perp}^{\prime}+\varepsilon_{\|}^{\prime}}{2}$ & $\sigma\left(\varepsilon_{\|}^{\prime}\right) / \sigma\left(\varepsilon_{\perp}^{\prime}\right)$ & $\sigma\left(\varepsilon_{\perp}^{\prime}-\varepsilon_{\|}^{\prime}\right)$ \\
\hline 45.450 & 0.40000 & 0.40000 & 3.090 & 3.090 & 0.000 & 3.090 & 0.086 & 0.086 \\
\hline 190.415 & 2.10000 & 2.10000 & \multicolumn{3}{|c|}{ Reference horizon $s_{0}$ resp. $t_{0}$} & & & \\
\hline 258.550 & 2.93330 & 2.93330 & 3.361 & 3.361 & 0.000 & 3.361 & 0.190 & 0.190 \\
\hline 436.370 & 5.00000 & 5.00000 & 3.124 & 3.124 & 0.000 & 3.124 & 0.051 & 0.051 \\
\hline 484.100 & 5.60000 & 5.60000 & 3.191 & 3.191 & 0.000 & 3.191 & 0.043 & 0.043 \\
\hline 587.390 & 6.80000 & 6.80000 & 3.150 & 3.150 & 0.000 & 3.150 & 0.032 & 0.032 \\
\hline 708.210 & 8.23330 & 8.23330 & 3.152 & 3.152 & 0.000 & 3.152 & 0.024 & 0.024 \\
\hline 849.980 & 9.94998 & 9.94998 & 3.183 & 3.183 & 0.000 & 3.183 & 0.019 & 0.019 \\
\hline 980.170 & 11.46700 & 11.50000 & 3.161 & 3.183 & 0.022 & 3.172 & 0.016 & 0.016 \\
\hline 1005.700 & 11.78333 & 11.81665 & 3.170 & 3.192 & 0.022 & 3.181 & 0.015 & 0.015 \\
\hline 1161.800 & 13.65000 & 13.68335 & 3.177 & 3.195 & 0.018 & 3.186 & 0.013 & 0.013 \\
\hline 1219.400 & 14.33330 & 14.36670 & 3.176 & 3.193 & 0.017 & 3.184 & 0.012 & 0.012 \\
\hline 1910.150 & 22.53330 & 22.60000 & 3.172 & 3.193 & 0.021 & 3.182 & 0.007 & 0.007 \\
\hline 2027.265 & 23.90000 & 23.96670 & 3.165 & 3.184 & 0.019 & 3.175 & 0.007 & 0.007 \\
\hline 2041.890 & 24.08335 & 24.15000 & 3.168 & 3.187 & 0.019 & 3.177 & 0.007 & 0.007 \\
\hline$s / m$ & $t_{\|} / \mu \mathrm{s}$ & $t_{\perp} / \mu \mathrm{s}$ & $\varepsilon_{\|}^{\prime}$ & $\varepsilon_{\perp}^{\prime}$ & $\varepsilon_{\perp}^{\prime}-\varepsilon_{\|}^{\prime}$ & $\frac{\varepsilon_{\perp}^{\prime}+\varepsilon_{\|}^{\prime}}{2}$ & $\sigma\left(\varepsilon_{\|}^{\prime}\right) / \sigma\left(\varepsilon_{\perp}^{\prime}\right)$ & $\sigma\left(\varepsilon_{\perp}^{\prime}-\varepsilon_{\|}^{\prime}\right)$ \\
\hline 849.980 & 9.94998 & 9.94998 & \multicolumn{3}{|c|}{ Reference horizon $s_{0}$ resp. $t_{0}$} & & & \\
\hline 980.170 & 11.46700 & 11.50000 & 3.051 & 3.185 & 0.134 & 3.118 & 0.095 & 0.096 \\
\hline 1005.700 & 11.78333 & 11.81665 & 3.114 & 3.229 & 0.114 & 3.172 & 0.080 & 0.081 \\
\hline 1161.800 & 13.65000 & 13.68335 & 3.164 & 3.221 & 0.057 & 3.192 & 0.040 & 0.040 \\
\hline 1219.400 & 14.33330 & 14.36670 & 3.163 & 3.212 & 0.048 & 3.188 & 0.034 & 0.034 \\
\hline 1910.150 & 22.53330 & 22.60000 & 3.165 & 3.199 & 0.034 & 3.182 & 0.012 & 0.012 \\
\hline 2027.265 & 23.90000 & 23.96670 & 3.155 & 3.185 & 0.030 & 3.170 & 0.011 & 0.011 \\
\hline 2041.890 & 24.08335 & 24.15000 & 3.159 & 3.189 & 0.030 & 3.174 & 0.011 & 0.011 \\
\hline
\end{tabular}

